\title{
Confabulation, delusion, and anosognosia: Motivational factors and false claims
}

\author{
Ryan McKay ${ }^{1,2}$ and Marcel Kinsbourne ${ }^{3}$ \\ ${ }^{1}$ Institute for Empirical Research in Economics, University of Zürich, Zürich, \\ Switzerland, ${ }^{2}$ Centre for Anthropology and Mind, University of Oxford, \\ Oxford, UK, ${ }^{3}$ Department of Psychology, The New School, New York, USA
}

\begin{abstract}
False claims are a key feature of confabulation, delusion, and anosognosia. In this paper we consider the role of motivational factors in such claims. We review motivational accounts of each symptom and consider the evidence adduced in support of these accounts. In our view the evidence is strongly suggestive of a role for motivational factors in each domain. Before concluding, we widen the focus by outlining a tentative general taxonomy of false claims, including false claims that occur in clinical settings as well as more garden-variety false claims, and incorporating both motivational and nonmotivational approaches to explaining such claims.
\end{abstract}

Keywords: Anosognosia; Confabulation; Delusion; Motivational processes

Patients in neurological and psychiatric settings are known to make rather striking claims. Consider the following two examples:

1. "I am the left foot of God."

2. "My father is $95-96$. My mother is 10 years younger so she is $85-86$."

The first claim is striking because it is bizarre and grandiose, but also because the individual who made it was a brilliant mathematician who went on to win a Nobel prize (see Nasar, 1998). In contrast, the striking nature of

Correspondence should be addressed to Dr Ryan McKay, Centre for Anthropology and Mind, University of Oxford, 51-53 Banbury Road, Oxford OX2 6PE, UK. E-mail: ryantmckay@mac.com

$\mathrm{RM}$ was supported by a research fellowship as part of a large collaborative project coordinated from the Centre for Anthropology and Mind (http://www.cam.ox.ac.uk) at the University of Oxford and funded by the European Commission's Sixth Framework Programme ("Explaining Religion"). Thanks to Katerina Fotopoulou for valuable discussions, and to those who organised and participated in the Delusions and Confabulations workshop, held at Macquarie University in July 2007. We also acknowledge the helpful comments of two anonymous reviewers.

(C) 2009 Psychology Press, an imprint of the Taylor \& Francis Group, an Informa business http://www.psypress.com/cogneuropsychiatry

DOI: $10.1080 / 13546800903374871$ 
the second claim requires some context to appreciate. At the time he made this statement, this man's parents had been dead for years (and had died in their seventies - see Moscovitch, 1995, p. 228).

How are we to account for such claims? And how can we characterise them? According to the scientific literature, the first example is considered to reflect a delusion (David, 1999), whereas the second is a paradigmatic instance of confabulation arising in the context of memory impairment (Moscovitch, 1995). The problem from a theoretical perspective is that it is not clear what the distinctions are between these two classes of symptom, nor what the nature of the overlap is between them, if any. This is most obvious when one considers that certain patient presentations are thought of as involving delusion in some circles, and confabulation in others. An example is anosognosia, which involves unawareness or denial of disease or disability, in particular denial of left hemiplegia following right-hemisphere brain damage. Recent authors have explicitly characterised this condition as either delusion (e.g., Aimola Davies, Davies, Ogden, Smithson, \& White, 2009; Davies, Aimola Davies, \& Coltheart, 2005) or confabulation (e.g., Heilman, 2009; Hirstein, 2005).

One feature common to confabulation, delusion, and anosognosia is that each of these symptoms typically involves some sort of false public claim. There may be exceptions to this-for example, delusions are usually conceptualised as false beliefs (cf. Hamilton, 2007; Stephens \& Graham, 2004), and beliefs can be kept private. On the other hand, it is typically because of the public declarations of deluded individuals that delusions attract clinical attention. Another exception involves the fact that delusions and confabulations might be, as it were, "serendipitously" true. A patient may lack access to his biographical information, yet by chance may confabulate the correct answer when asked his age. Such exceptions aside, false claims are a key feature of these disorders. Our primary aim in this paper is to consider the role of motivational factors in such claims. In the sections that follow we will discuss motivational accounts of confabulation, delusion, and anosognosia. Before concluding, we will widen the focus by outlining a tentative general taxonomy of false claims, including false claims that occur in clinical settings as well as more garden-variety false claims, and incorporating both motivational and nonmotivational approaches to explaining such claims.

\section{MOTIVATIONAL ACCOUNTS}

What are motivational factors? In essence, they are goal-directed states or processes such as desires and intentions: processes that generate and structure action (Bayne \& Fernández, 2009). Bayne and Fernández (2009) 
contrast such "telic" processes with "thetic" processes that provide, or at least aim to provide, a veridical representation of the world. Whereas thetic states (aim to) represent the way the world is, telic states (insofar as they are representational) represent the way we would like the world to be.

A complication here stems from the fact that our ideal world might be a world in which we have accurate representations of reality. We therefore invoke a further distinction (although not much will turn on it here), a distinction between representations and metarepresentations:

- Thetic representations represent the way the world actually is. Example: "I believe that I am a poor athlete."

- Telic representations represent the way we would like the world to be. Example: "I wish that I were a great athlete."

- Thetic metarepresentations represent our thetic and telic representations. Examples: (1) "I believe that some of my beliefs are false (although I don't know which ones specifically)"; (2) "I believe that I like chocolate."

- Telic metarepresentations represent the kinds of thetic and telic representations we would like to have. Examples: (1) "I wish that all of my beliefs were true"; (2) "I wish that I liked broccoli."

On our definition, motivational accounts of symptoms at the interface of psychiatry and neurology (e.g., delusions, confabulations) are accounts of such symptoms that implicate the motivationally biased handling of evidence (Mele, 1997; see also Davies, 2009). In such accounts, the symptoms in question arise when telic factors figure unduly ${ }^{1}$ in the formation of thetic representations (or metarepresentations). Moreover, the symptoms are viewed as conferring some kind of psychological benefit, and this is their raison d'être. In some instances the symptoms may be seen as reflecting efforts to disarm inner threats and to defuse tension. In other instances the putative goal may be to reduce confusion and ambiguity.

\footnotetext{
${ }^{1}$ What do we mean by "unduly"? An example may serve to clarify. Imagine that a scientist, motivated by a desire for certainty (see later), conducts an experiment to investigate which of two theories best explains a given phenomenon. She runs the experiment, but sadly the results she obtains are utterly equivocal. However, her desire for certainty is sufficiently strong that her consideration of her evidence is motivationally biased: instead of admitting that her data are completely inconclusive, she concludes that the evidence favours one theory over the other. This conclusion (a thetic representation) has stemmed from her desire for certainty (a telic factor: specifically a telic metarepresentation), both in the sense that this factor provided the original impetus for conducting the experiment and in the sense that this factor biased her handling of the evidence. It is only in the second sense, however, that the telic factor has figured unduly in the formation of the thetic representation.
} 
In contrast, proponents of nonmotivational accounts do not view psychoneurological symptoms as having a raison d'etre - at least not in the teleological sense. Rather, these symptoms are viewed as representing functionless - indeed, dysfunctional-departures from normal operation. This is the pure neuropsychological deficit perspective (note that an integrated motivational and deficit perspective is also possible; see later). From the purely deficit perspective the symptoms do, however, have a "reason for being" in the mechanical, aetiological sense - they stem from abnormalities in ordinary cognitive processes, underpinned by damage or disruption to the brain.

We turn now to a brief consideration of some recent evidence for motivational accounts of confabulation.

\section{MOTIVATIONAL ACCOUNTS OF CONFABULATION}

Broadly speaking, there are two main types of motivational account where confabulation is concerned. In the first place, a number of authors have suggested that some patients confabulate in order to conceal embarrassing gaps in their memories. This "gap-filling" hypothesis has a long history (e.g., Bonhoeffer, 1901), but to date there is very little evidence that the theory is valid, at least as a general account (see Schnider, 2008, for a review). Note, in any case, that this account only qualifies as "motivational" in our terms if individuals confabulate so as to conceal memory gaps from themselves. This is because attempts to conceal memory gaps from others need not involve any departure from rationality. Patients who are cognisant of their memory gaps may seek to influence the thetic representations of others with respect to these lacunae, but this goal does not require the motivationally biased handling of evidence. Note also that a purely gap-filling account need make no prediction regarding the emotional valence of confabulatory content. If patients are motivated by a desire to avoid revealing (to themselves?) the limitations of their memories, the key consideration should be to paper over embarrassing gaps with plausible content, whether positive or negative. Yet confabulations are frequently implausible (and indeed frequently impossible).

In contrast, other authors have claimed that confabulations are purposive constructions that function to embellish the situation of the patient (e.g., Conway \& Tacchi, 1996). On this view, confabulations are compensatory not (or not merely) by virtue of their existence, but via their motivated content. Purely motivational variants explain both the existence and the content of confabulation in motivational terms. Integrated variants, on the other hand, incorporate a role for both motivational and nonmotivational factors. For example, Fotopoulou and colleagues (see Fotopoulou, 2010 this issue, for an overview) have suggested that self-serving confabulations are prominent 
because impairments in executive processes responsible for the inhibition of previously rewarded responses lead to the preferential selection of personally rewarding representations (e.g., memory representations). Whether pure or integrated, motivational accounts of the second type make specific predictions regarding the emotional valence of confabulations - that they should be positively biased, and in particular more positively biased than the memory distortions of healthy control participants. Fotopoulou and colleagues have tested these predictions in a number of systematic empirical investigations, two of which we outline here (see Fotopoulou, 2010 this issue, and Metcalf, Langdon, \& Coltheart, 2010 this issue, for reviews of other recent studies, and for more thorough general treatments of the role of motivational factors in confabulation).

First, Fotopoulou, Conway, Griffiths, Birchall, and Tyrer (2007) investigated the provoked confabulations of a 60 -year-old male patient ("LH") who had undergone surgical clipping of an anterior communicating artery (ACoA) aneurysm. A CT angiographic study performed 10 days postsurgery had revealed a large acute infarction within LH's left frontal lobe, including both the dorsolateral and ventromedial prefrontal cortex. On clinical examination 4 months postsurgery he presented as talkative, hyperactive, verbally disinhibited, amnesic, and densely anosognosic. LH's confabulations at this time appeared to be wishful and self-aggrandising. For example, he claimed that he was in a holiday resort and treated hospital staff accordingly. To substantiate this clinical impression of his confabulations, LH and five neurologically healthy age-, sex-, and education-matched control participants were each asked to describe a series of "self-defining" events, including high and low points of their lives, turning points, and earliest memories. The resulting protocols were coded for valence, and separate interviews held with participants' relatives and staff provided corroborating information for the reported memories. The authors found that the confabulations produced by LH in this paradigm were significantly more positively valenced than both his true memories and the memories of the control participants.

In a subsequent investigation (Fotopoulou et al., 2008), false memories were elicited in 10 severely amnesic confabulating patients, 10 healthy ageand education-matched controls, and four amnesic nonconfabulating controls. Control participants were asked to deliberately alter true self-referential memories in order to create false memories. Memory protocols drawn from interviews with these groups were later coded for valence: raters indicated, on a 7-point scale, whether self-representations in the confabulated events were positive/self-enhancing, or negative/self-diminishing, relative to the relevant self-representations in the corresponding "reality" (as gleaned, for confabulators, by information provided by relatives, staff, or medical files). The authors found that the false memories of the confabulating patients distorted 
previous experiences in a significantly more pleasant and self-enhancing manner than those of controls.

To summarise, two main classes of motivational explanation exist for confabulation. The first hypothesis, that patients confabulate to conceal gaps in their memories, has garnered little empirical support. The second hypothesis, however, that confabulations reflect the operation of processes that embellish the patient's situation, looks more promising. A series of studies are suggestive of a systematic positive bias in the emotional valence of confabulations. Importantly, there is evidence that such biases exceed those displayed by healthy control participants. Although evidence of a positive bias is consistent with a purely motivational account of confabulation, Fotopoulou and colleagues favour a more nuanced account that integrates both motivational factors and neuropsychological impairments.

\section{MOTIVATIONAL ACCOUNTS OF DELUSION}

\section{The Capgras, Cotard, and Frégoli delusions}

We begin this section by outlining motivational accounts of three intriguing delusions - the Capgras, Cotard, and Frégoli delusions. Consider, first, the Capgras delusion. Capgras patients believe that an impostor has replaced a person close to them. In an early formulation of this condition, Capgras and Carette (1924) described a young woman's impostor delusions as representing an attempt to veil incestuous desires for her father. The suggestion here seemed to be that in coming to believe that the object of her desire was actually a fraudulent impersonator of her father, the woman had found a way of rendering her desire acceptable (sexual desire is not so troubling if the object of desire is merely impersonating a family member). Converting an unacceptable desire into an acceptable desire was thus the proposed raison d'être of this woman's delusion.

Now consider Cotard syndrome, which can involve the conviction that one is dead or has ceased to exist (Cotard, 1882; Young \& Leafhead, 1996). A motivational account of this condition can be found in Enoch and Ball (2001), who suggest that it may serve the protective function of reducing existential anxiety caused by awareness of mortality (cf. Becker, 1973; Greenberg, Pyszczynski, \& Solomon, 1986). If one is already dead or does not exist, then one cannot fear death or the future cessation of existence (a kind of "you-can't-fire-me-because-I-quit" strategy). Such seems to be the spirit of Enoch and Ball's formulation.

Finally, consider the Frégoli delusion. Patients with this delusion believe that they are being followed about by a familiar person who is in disguise and thus unrecognisable (Davies \& Coltheart, 2000; cf. Banov, Kulick, Oepen, \& Pope, 1993). Collacot and Napier (1991; cited in Mojtabai, 1994) 
put forward a motivational account of this delusion. The case was a woman who had misidentified certain strangers as her deceased father. According to Collacot and Napier, the woman's delusion represented an attempt to fulfil a wish that her father still be alive. Transforming an intolerable reality into a desired reality was thus the proposed raison d'être of her delusion.

What are we to make of accounts such as these? One criticism is that some of these accounts can get very convoluted. The subject of the Capgras formulation just described, for example - the woman with the delusion about her father-also believed that impostors had replaced her mother, brother, uncle, and aunt (de Pauw, 1994). It would seem necessary, therefore, to have postulated additional incestuous fantasies if the theory in question was to hold. The Cotard and Frégoli formulations also seem rather convoluted. If you are afraid of death, why not adopt the belief that you are immortal? This seems a happier solution (and no less realistic) than to adopt the belief that you are already dead. If grief is intolerable, why not believe that your departed loved one is in heaven? This seems more comforting, and less confusing, than the belief that your loved one would follow you around in disguise. Of course, many people do believe in immortality and heaven, and many others have argued that telic factors figure unduly in the formation of such thetic representations. But this just underscores the point with regard to the Cotard and Frégoli delusions - if a culturally sanctioned belief system already provides the relevant psychological benefits, why seek these benefits in exotic beliefs that are likely to be opposed at every turn?

Whatever credibility these motivational formulations might have for the cases in question, they seem implausible as general theoretical accounts. The sexual desire formulation of Capgras, for example, seems hard-pressed to explain all reported cases. After all, impostor delusions have been reported for a range of animals including a dog (Raschka, 1981), a cat (Reid, Young, \& Hellawell, 1993), a parrot (Somerfield, 1999), and a canary (Rosler, Holder, \& Seifritz, 2001). There are also reports of cases involving inanimate objects such as tools and ornaments (see Ellis et al., 1996). A second example is that the wish fulfilment account of Frégoli delusion struggles to explain Frégoli cases where strangers are misidentified as familiar, but hostile, individuals. Proponents of motivational accounts might point out that their accounts are not intended as stock explanations, applicable to each and every occurrence of the delusions in question. But if motivational accounts are to be useful, they should at least be testable — not simply assembled ad hoc.

Interestingly, a single testable framework exists that may potentially explain all three of these delusions - a framework that is not motivational but purely neuropsychological. Briefly, the framework implicates disrupted connections between face-processing areas and the limbic system in the 
formation of these delusions (Ellis \& Young, 1990; Langdon \& Coltheart, 2000; Stone \& Young, 1997; although see Hirstein, 2010 this issue, for an alternate interpretation). Such disruptions are thought to generate discrepancies between visual and autonomic familiarity data. In the case of Capgras delusion, visually familiar others may be rendered autonomically unfamiliar, an incongruence that the impostor belief may be generated to explain. In their original description, Capgras and Reboul-Lachaux (1923) related that their patient had developed a feeling of strangeness when viewing the faces of familiar people. So the conclusion that there are doubles is a judgement explained in part by emotional factors (which is not to say that emotion biases the patient's treatment of the unusual emotional data; see Mele, 2009). A study conducted by Ellis, Young, Quayle, and de Pauw (1997) provided empirical evidence consistent with this proposal. These researchers recorded skinconductance responses (SCRs) while showing Capgras patients and control participants a series of predominantly unfamiliar faces, with occasional familiar faces interspersed. Whereas control participants showed significantly greater SCRs to familiar faces than unfamiliar faces, Capgras patients showed SCRs of equivalent magnitude to photographs of both types (see also Brighetti, Bonifacci, Borlimi, \& Ottaviani, 2007; Hirstein \& Ramachandran, 1997).

Young and colleagues (e.g., Wright, Young, \& Hellawell, 1993; Young, 2000; Young \& Leafhead, 1996; Young, Leafhead, \& Szulecka, 1994) have suggested that a disjuncture between visual and autonomic data may be a causal feature of Cotard delusion as well as of Capgras delusion. The difference, they maintain, is a matter of the individual's prevailing attributional style. Whereas Capgras patients make external attributions for the incongruous data (e.g., "that woman is not my wife, she's a stranger who looks just like her - an impostor"), Cotard patients make internal attributions (e.g., "that woman looks like my wife but doesn't 'feel' like her-I must be dead").

The latter attribution, it must be said, seems rather unlikely - involving an extravagant logical leap. Ramachandran and Blakeslee (1998; see also Gerrans, 2000, 2002) favour a different proposal, that whereas Capgras delusion involves disruption to pathways underpinning the emotional component of face recognition, Cotard delusion involves a more global disconnection of all sensory areas from the limbic system. This would result in a fundamentally altered experience of the world, in light of which the belief that one has died might not seem so outlandish. Although on the face of it this proposal is perhaps more credible than the Young et al. attributional hypothesis, a recent study by McKay and Cipolotti (2007) found evidence consistent with the latter-namely, a pronounced internalising attributional bias in a patient with Cotard delusion. More research is needed here-in 
particular, it would be useful to investigate whether Cotard patients do in fact show deficits in autonomic arousal, and if so whether these deficits are restricted to facial stimuli or whether they involve a more global loss of autonomic responsiveness to all familiar stimuli.

Finally, the discrepant familiarity data framework can also be plausibly extended to the Frégoli delusion. Whereas the evidence outlined previously suggests that the Capgras delusion stems from a diminished affective response to known faces (visual familiarity in the absence of autonomic familiarity), Ramachandran and Blakeslee (1998; cf. Christodoulou, 1976, 1977; Feinberg \& Keenan, 2005) proposed that the Frégoli delusion may be generated to explain a heightened affective response to unfamiliar faces (autonomic familiarity in the absence of visual familiarity). Although this specific hypothesis is yet to be investigated, the appeal of the neuropsychological familiarity data framework lies in its testability (where Capgras delusion is concerned, predictions have already been tested and confirmed), plausibility (in contrast to the rather extravagant motivational stories outlined earlier) and parsimony (three separate delusions are accommodated in a single framework). For these reasons, motivational accounts of these delusions have been rendered largely obsolete (although, given the neuropsychological disorder, the surface manifestations might well vary from case to case due to idiosyncratic motivational factors).

Before we move on, we wish to emphasise that the discrepant familiarity data theory is not without its own problems. Regarding Capgras, for example, some account needs to be given of the (variable) selectivity of impostor delusions. Although many Capgras patients believe that multiple others have been replaced by impostors (one of Ellis et al.'s, 1997, patients had "Capgras for virtually the entire town of residence", p. 1087), others misidentify just a single individual. Presumably the reason for this variability is that the extent of autonomic disruption is variable across patients. For patients with minor disruption, therefore, the discrepancy between visual and autonomic familiarity would only be significant for highly familiar others (those emotionally close to the patient), whereas more major disruptions would generate more widespread discrepancies ("virtually the entire town of residence"). However, given that the patients in the Ellis et al. study showed a diminished affective response to pictures of famous people, why did none of them claim that these were pictures of impostors?

A second problem concerns the claim that Capgras delusion implicates pathways underpinning the emotional component of face recognition. Some cases of Capgras do not involve face perception at all-for example, Reid et al. (1993) described the case of a blind woman with Capgras, and we have already noted that misidentification can occur for inanimate objects. Such cases call for explanations involving different recognition systems (see Ellis 
et al., 1996). We mention this fact not to discredit such accounts, but merely to show that neuropsychological accounts can also quickly become convoluted when the range of different patient presentations is taken into consideration. We are not sure, however, how a purely neuropsychological account would explain the case of a woman who believed that she was pregnant with an impostor foetus ... (Silva, Leong, Longhitano, \& Botello, 1991).

\section{Persecutory delusions}

Motivational accounts need not be convoluted. And for some delusions they seem quite natural:

Consider the delusion of erotomania (de Clérambault's delusion), in which the patient forms the belief that someone of higher social status is secretly in love with him or her... This delusion quite obviously cries out for a motivational explanation ... (Bayne \& Fernández, 2009, p. 13).

As we indicated earlier, however, if motivational accounts are to be accepted they must be tested empirically — not just constructed ad hoc. With respect to motivational accounts of delusions, the most systematic experimental work has focussed on persecutory delusions, and especially on the psychodynamically inflected motivational formulation of Bentall and colleagues (see, for example, Bentall \& Kaney, 1996; Kinderman \& Bentall, 1996, 1997; see also McKay, Langdon, \& Coltheart, 2007a, who chart the evolution of this theory through increasingly complex conceptions).

Persecutory delusions are the most common delusional subtype. According to the classic psychodynamic conception, paranoid symptoms are occasioned by defensive attempts to escape intolerable feelings of shame and culpability by projecting them onto others (see McWilliams, 1994). Any sense of personal guilt or failure is transformed into dangers that threaten from outside, and the deluded individual assuages his or her sense of personal inadequacy at the cost of living in a world replete with hostile, malevolent agents (Adler, 1914/1929; Bell, 2003; Freud, 1895; Zigler \& Glick, 1988). Notwithstanding differing conceptions of the syntax of the putative projective process (see McKay et al., 2007a), the formulation of Bentall et al. retains certain elements of this classic notion, particularly the idea that paranoid individuals impute malicious intentions to others so as to evade conscious awareness of negative self-representations. In brief, Bentall and colleagues have claimed that persecutory delusions are constructed defensively, for the preservation of explicit self-esteem. A key prediction of their model is that persecutory delusions will occur in association with 
discrepancies between relatively high measures of conscious, explicit selfesteem and relatively low measures of unconscious, implicit self-esteem. ${ }^{2}$

A number of studies have attempted to test this prediction. Kinderman (1994), for example, used an "emotion" version of the Stroop test (Stroop, 1935) to measure preconscious attentional biases to different word types. Participants in this task are required to name the colours of various words; because colour naming is typically slowed for emotionally salient words, response speeds can be used to index the degree to which the emotional salience of a word (or concept) has interfered with performance. Kinderman found that although persecutory deluded individuals rated positive personally descriptive adjectives as more self-relevant than negative adjectives, they showed an attentional bias (as indexed by degree of colour-naming interference) for the negative adjectives. According to Kinderman, this discrepancy reflected the operation of a defensive process associated with discrepancies between high explicit and low implicit self-esteem. Garety and Freeman (1999), however, have critiqued this interpretation of Kinderman's results. These authors noted that the persecutory deluded group in Kinderman's study did not differ from a depressed psychiatric comparison group in terms of explicit self-relevance ratings of negative adjectives. Garety and Freeman thus questioned the suggestion that Kinderman's persecutory deluded participants showed high self-esteem on the ratings task.

In a different attempt to demonstrate explicit/implicit self-esteem discrepancies in persecutory deluded individuals, Lyon, Kaney, and Bentall (1994) presented paranoid patients with two measures of attributional style. Attributional style refers to one's tendency to generate certain types of explanations for events - for example, one's tendency to regard events as being caused by oneself versus caused by external factors. One of the administered measures was a parallel form of the Attributional Style Questionnaire (ASQpf; Peterson et al., 1982), which functioned as a transparent (explicit) measure of attributional style. This questionnaire comprises brief descriptions of 12 hypothetical events. Half are positive events (e.g., "You become very rich") and half are negative (e.g., "You go out on a date and it goes badly"). Respondents are instructed to vividly imagine each event and to write down what they feel would be the major cause of each situation. They are then required to rate each cause along different attributional dimensions (e.g., internality-externality).

\footnotetext{
${ }^{2}$ Italicisation of relatively here denotes the "weaker" formulation of the Bentall et al. account (Garety \& Freeman, 1999), whereby explicit self-esteem is high relative to implicit self-esteem (in the "stronger" formulation explicit self-esteem is high — and implicit self-esteem low-relative to that of healthy individuals). The weaker formulation provides for scenarios where persecutory delusions only partially fulfil their putative defensive function, and explicit self-esteem is not fully preserved.
} 
The other measure Lyon and colleagues administered was the Pragmatic Inference Task (PIT; Winters \& Neale, 1985), an opaque (implicit) measure of attributional style based on the original ASQ but presented as a memory test. Although persecutory deluded individuals displayed a self-serving attributional style on the ASQpf (being more inclined to take the credit for positive events and to attribute negative events to external factors), their responses on the PIT were decidedly non-self-serving (taking responsibility for negative events and attributing positive events to external factors). This seems quite a successful demonstration of an explicit-implicit discrepancy, albeit a discrepancy between explicit and implicit attributions rather than explicit and implicit self-evaluations. Unfortunately, however, attempts to replicate this finding have not been successful (Krstev, Jackson, \& Maude, 1999; Martin \& Penn, 2002; Peters, Day, \& Garety, 1997).

The delusion-as-defence account of Bentall and colleagues holds that paranoid individuals are motivated to prevent conscious awareness of negative implicit self-representations. A successful test of this theory therefore requires elicitation of such implicit representations, which is a challenge methodologically. Two recent studies (McKay et al., 2007a; Moritz, Werner, \& von Collani, 2006) have approached this problem by using the popular and influential Implicit Association Test (IAT; Greenwald, McGhee, \& Schwartz, 1998).

The IAT is a computerised task designed to measure the relative strengths of automatic interconcept associations. In the crucial conditions of the task words from four different categories are flashed randomly onto the computer screen (e.g., self words, other words, pleasant words, and unpleasant words). Participants are instructed to press (say) a right key on the keyboard if the word is a self word (e.g., me, myself) or a pleasant word (e.g., freedom, rainbow) and to press a left key if the word is an other word (e.g., they, them) or an unpleasant word (e.g., vomit, murder) (for illustration see Table 1). Faster responding to a particular pairing of the concepts is assumed to index a stronger association between those concepts. The particular categories

TABLE 1

Sample items from one of the crucial conditions of an Implicit Association Test (IAT) for implicit self-esteem

\begin{tabular}{lcc}
\hline Left key category label & Sample items & Right key category label \\
\hline Other or unpleasant & & Self or pleasant \\
$* * *$ & Myself & $* * *$ \\
& Vomit & $* * *$ \\
$* * *$ & Rainbow & \\
\hline
\end{tabular}

Asterisks indicate correct responses. 
described here feature in an IAT for implicit self-esteem, and were first investigated by Greenwald and Farnham (2000). These authors showed that the relative ease of making judgements when the self and pleasant categories are combined (in which case other is paired with unpleasant) can be used to index a participant's implicit self-esteem (individuals with higher implicit selfesteem should find categorisations easier when self and pleasant are paired than when self and unpleasant are paired).

In order to test the predicted association between persecutory delusions and explicit/implicit self-esteem discrepancies, both Moritz et al. (2006) and McKay et al. (2007a) administered the IAT for implicit self-esteem to persecutory deluded patients. Moritz et al. found that patients with schizophrenia (with or without current persecutory delusions) had lower implicit self-esteem than healthy control participants. Although the explicit self-esteem of their persecutory deluded patients was also markedly lower than that of the controls, it was higher than that of nonparanoid patients with schizophrenia. In the McKay et al. study, paranoid patients were found to have lower implicit self-esteem than healthy controls and remitted patients, in that the response advantage for the condition combining self and pleasant was significantly reduced for this group (see Figure 1). On two measures of explicit self-esteem, however, the persecutory deluded group did not differ significantly from the other groups once appropriate adjustments had been made for levels of comorbid depression. This was necessary since people who are depressed report low levels of explicit self-esteem.

The results of these two studies are consistent with the Bentall et al. suggestion that persecutory delusions are associated with a discrepancy between explicit and implicit self-esteem, and they accord with psychodynamic accounts of paranoia dating back to Freud (1895) and Adler (1914/1929).

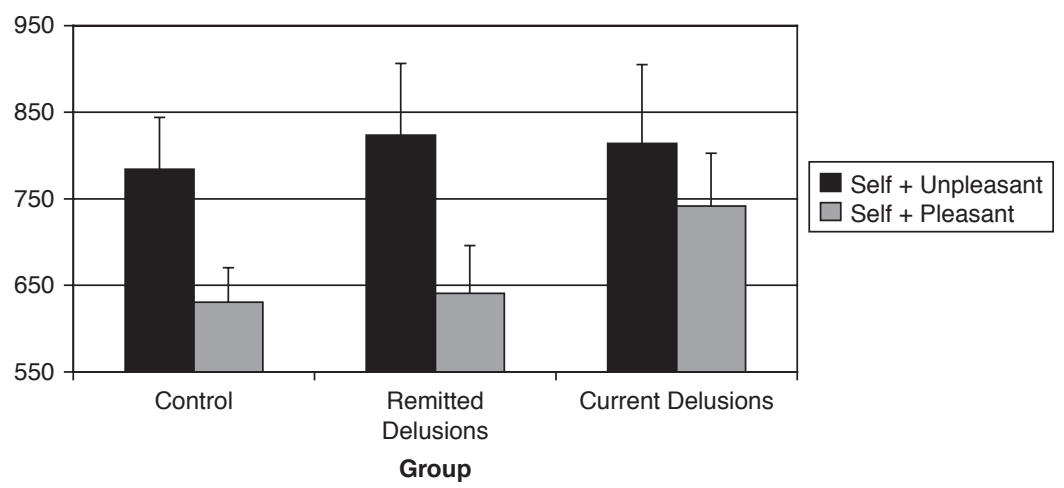

Figure 1. Results of the McKay et al. (2007a) IAT study. The bars show the mean response latencies of each experimental group for the two crucial IAT conditions (self/pleasant vs. self/unpleasant). 
However, a more recent study by Vazquez, Diez-Alegria, HernandezLloreda, and Moreno (2008) failed to find any evidence of a discrepancy between explicit and implicit measures of self-concept in patients with acute and remitted persecutory delusions. One of the explicit measures used here was a task requiring endorsement of self-relevant adjectives; the implicit measure comprised a free recall test of the same adjectives. More experimentation is clearly required to resolve the discrepancies between these studies.

\section{Grandiose delusions}

Although the notion that delusions are a defence against low self-esteem has been most systematically applied to persecutory delusions, the applicability of the idea to grandiose delusions is perhaps more obvious, as the latter typically appear more self-enhancing than persecutory beliefs (Smith, Freeman, \& Kuipers, 2005). Zigler and Glick (1988) have suggested that the grandiose delusions observed in mania represent a "camouflaged depression", a proposal that accords with Jordan, Spencer, Zanna, Hoshino-Browne, and Correll's (2003) discussion of narcissistic grandiosity: "[N]arcissists are viewed as simultaneously holding positive conscious self-views while harbouring significant self-doubts at less conscious levels ..." (p. 970). Using the IAT, Jordan et al. found that nonclinical participants with high explicit but low implicit self-esteem showed significantly more narcissism than individuals high in both explicit and implicit self-esteem (but see Campbell, Bosson, Goheen, Lakey, \& Kernis, 2007). Given that grandiose delusions might be construed as involving "clinically significant narcissism", might one expect individuals with delusions of grandeur to show discrepancies between explicit and implicit self-esteem?

We know of only a single published study that has directly addressed this question to date, with negative results. Smith et al. (2005) administered explicit and implicit measures of self-esteem to individuals with grandiose delusions and healthy controls and failed to find any evidence of a selfesteem discrepancy in the grandiose patients. Implicit self-esteem here was gauged by measuring recall of low self-esteem words and by measuring the speed with which participants named the colours of depression-related words relative to neutral words.

A separate investigation by Lyon, Startup, and Bentall (1999), however, is worth considering in this regard. Adapting the methodology of their earlier investigation of persecutory delusions (already outlined; Lyon et al., 1994), Lyon et al. (1999) presented two measures of attributional style (the ASQpf as an explicit measure and the PIT as an implicit measure) to a group of nondelusional, manic patients, as well as to matched depressed and healthy 
controls. With a direct administration of the ASQpf, the manic patients showed evidence of a self-serving attributional style (i.e., internal attributions for positive events and external attributions for negative events). The response of these same individuals on the PIT, however, was similar to that of the depressed controls and dissimilar to that of the healthy controls, and decidedly nonself-serving (i.e., being more inclined to make internal attributions for negative events and external attributions for positive events).

The relevance of this study for investigations of self-discrepancies in grandiose delusions is arguable. On the one hand, these authors tested manic bipolar patients rather than patients with grandiose delusions (and their paradigm taps underlying attributions rather than self-evaluations-as did the earlier study by Lyon et al., 1994). On the other hand, grandiosity is clearly a feature of both presentations, and indeed inflated self-esteem or grandiosity is the first symptom listed in the DSM-IV's Criterion B for a Manic episode (American Psychiatric Association, 2000). Seen in this light, the results of the study are tantalising and suggest that further investigation into connections between delusional grandiosity and self-esteem discrepancies may be worthwhile - perhaps using suitable adaptations of the IAT.

\section{Need for closure}

A number of ingenious motivational accounts have been proposed to explain delusional beliefs. In some cases, such as with the Capgras, Cotard, and Frégoli delusions, a disparate collection of exotic and convoluted accounts has been more or less superseded by a single neuropsychological frameworkalthough it is well to note that neuropsychological accounts can quickly become convoluted as well. What is key is that hypotheses should be framed in a testable fashion. The most systematic efforts to test motivational accounts to date have been seen in studies of persecutory delusions - although here too the evidence remains equivocal. Even if one accepts a defensive framework for delusions such as persecutory and grandiose delusions, however, many questions remain. One such question concerns the reasons for developing one delusion rather than another-if the aim is to preserve self-esteem, what explains why one patient develops grandiose delusions while another develops persecutory delusions? The former seem a more straightforward means of preserving self-esteem - but the latter are more common.

Perhaps the most robust evidence of motivational factors in the aetiology of delusions comes from investigations of a so-called "need for closure", a construct associated with a preference for certainty and predictability (Kruglanski, 1989). Individuals who are highly motivated to seek an explanation for anomalous experiences may prefer any explanation-even a deluded one-rather than none at all (Colbert \& Peters, 2002). This 
suggestion parallels the gap-filling account of confabulation in that both explanations are hedonically noncommittal - neither makes any prediction regarding the emotional valence of confabulatory or delusional content (see Davies, 2009). Note that a need for closure is an epistemic motive - in our terminology it constitutes a telic metarepresentation, i.e., it represents a preference for any thetic representation of a given state of affairs rather than none at all.

What is the evidence for an association between delusions and need for closure? Colbert and Peters (2002) examined need for closure in nonclinical participants who were screened for delusion-proneness using the Peters et al. Delusions Inventory (PDI-21; Peters, Day, \& Garety, 1996). They found that delusion-prone individuals (those scoring in the upper quartile on the PDI) scored significantly higher on need for closure than nondelusion-prone (lower quartile) individuals. Need for closure was assessed with the Need for Closure Scale (NFCS; Webster \& Kruglanski, 1994), a self-report measure containing five subscales: desire for predictability, need for order, intolerance of ambiguity, decisiveness, and closed-mindedness. A subsequent study by Bentall and Swarbrick (2003) investigated need for closure in a clinical sample: patients with either current or remitted persecutory delusions were compared to healthy controls. Both patient groups scored higher on need for closure than the control group, although no difference was found between the two patient groups. This pattern was observed for the five distinct facets of need for closure.

Later studies have replicated the reported connections between delusions and need for closure - although not with all facets of the latter. Neuberg, Judice, and West (1997) had argued that the NFCS assesses two separate dimensions: a desire for simple structure represented by the desire for predictability, need for order, and intolerance of ambiguity subscales, and a preference for quick, decisive answers captured by the decisiveness subscale. McKay, Langdon, and Coltheart (2007b) found that patients with a history of persecutory delusions scored higher than healthy control participants on the first of these dimensions, but did not show evidence of greater decisiveness (the findings of other studies are consistent with this pattern; see Colbert, Peters, \& Garety, 2006; Freeman et al., 2006). In fact, paranoid ideation has been found to be associated with greater indecisiveness in both clinical and nonclinical individuals (McKay, 2004).

What is the theoretical significance of this dissociation between decisiveness and a desire for simple structure? Individuals who desire simple structure dislike confusion, uncertainty, and ambiguity. By their very nature, however, decisions imply uncertainty - after all, a course of action is not certain if it requires a decision to be made. It may be, therefore, that whereas some individuals who desire "simple structure" make decisions quickly in order to terminate the stress of decision making and to achieve a sense of closure, 
others may avoid confronting the uncertainty that is part and parcel of any decision. Perhaps for the latter individuals, the uncertainty of a decision left unmade is preferable to uncertainty about the wisdom of a decision that has been made.

Avoidance is rarely an effective strategy for dealing with fear, however, so the latter group of people are likely to be somewhat dysfunctionalburdened with a strong aversion to ambiguity and uncertainty, yet unable to manage the inevitable uncertainties in life by making decisions to resolve them. In a speculative vein, one might conjecture that indecisive people fear the responsibility of making incorrect decisions, that they fear the culpability of a wrong choice. Continuing this speculation, one could contend that the link between indecisiveness and paranoia consists in the fact that they both provide dysfunctional means of avoiding (feelings of) culpability.

It may be that people high in paranoid ideation fear uncertainty and culpability, yet deal with these fears in dysfunctional ways - on the one hand by avoiding making conscious decisions, and on the other hand by automatically abrogating responsibility for negative events in their lives, attributing their misfortunes to the actions of malevolent others (Kinderman \& Bentall, 1997). Although speculative, these ideas accommodate the finding of links between paranoid ideation and indecision on the one hand, and paranoid ideation and desires for simple structure on the other. Future research may demonstrate whether these suggestions can bear up under further empirical scrutiny.

\section{MOTIVATIONAL ACCOUNTS OF ANOSOGNOSIA}

We noted earlier that anosognosia, which involves the denial of manifest disability - particularly denial of left hemiplegia - has been variously characterised as delusional and confabulatory. Some historically prevalent accounts of anosognosic denial (e.g., Weinstein \& Kahn, 1955) have held that it is employed defensively, to alleviate the distress occasioned by the unpleasant reality of disability. Such motivational accounts, however, have been subject to considerable criticism. In this section we briefly discuss two key criticisms of motivational accounts, and then consider evidence for such accounts.

\section{Hemispheric asymmetry}

A number of authors (e.g., Bisiach \& Geminiani, 1991; Stone \& Young, 1997) have highlighted a striking asymmetry in the expression of anosognosia for hemiplegia. Denial of hemiplegia is largely confined to cases of leftsided paralysis, and is seldom seen in right-sided paralysis. Such authors 
view this lateralisation as a major stumbling block for motivational accounts (there being no reason to suppose that right-sided paralysis should be any less upsetting than left-sided paralysis). It is true that this asymmetry would pose difficulties for a purely motivational account of anosognosia. But might such difficulties be bypassed through the adoption of an integrated motivational and neuropsychological deficit perspective?

Both Ramachandran (e.g., 1995; Ramachandran \& Blakeslee, 1998) and Turnbull (e.g., Turnbull, Jones, \& Reed-Screen, 2002; Turnbull \& Solms, 2007) have offered such a perspective, putting forward motivational theories of anosognosia that incorporate damage to right-hemispheric mechanisms. Ramachandran has argued that the left hemisphere is the neurological locus of psychological defence, and has suggested that the left-hemispheric mechanisms that underpin defensive processes may be opposed by complementary right hemispheric mechanisms. Operating normally, these complementary mechanisms would constrain the influence of defensive processes on belief formation. If these mechanisms were damaged, however-perhaps by an aneurysm or accident - patients would be left without constraints on their capacities for psychological defence. This would permit the flagrant denials observed in anosognosia.

Whereas Ramachandran's explanation (1995; Ramachandran \& Blakeslee, 1998) of anosognosia implicates a dysfunctionally enhanced capacity for managing negative emotions, Turnbull and Solms (2007) suggest that anosognosia involves an impaired ability to manage such emotions. Their proposal is that anosognosic patients fail to acknowledge their deficits because to do so would entail levels of aversive emotion that - because of damage to right-lateralised emotion-regulation systems - they could not tolerate. By incorporating damage to neurological structures that implement or constrain emotion regulation processes, accounts such as these defuse the asymmetry objection. If anosognosia results from an abnormality in the brain's management of negative emotions, an abnormality caused by damage to righthemispheric mechanisms, then one would not expect left-hemispheric damage to result in anosognosia.

\section{Selectivity}

One problem for such accounts, however, is that patients with anosognosia for left hemiplegia may freely acknowledge other impairments (Cutting, 1978), and may in fact be overtly hypochondriacal with respect to even minor ailments (Bisiach \& Geminiani, 1991; Kaplan-Solms \& Solms, 2000). Some authors (e.g., Turnbull et al., 2002) argue that this disparity reflects a disparity in the perceived seriousness of the ailments in question. For example, hemiplegia represents a far greater threat to bodily integrity than minor 
complaints such as insomnia and back pain, or even medical conditions such as diabetes. The overt hypochondria regarding minor ailments might even be a dissimulative manoeuvre, a defensive attempt to shift the focus from the true underlying concern (Weinstein \& Kahn, 1950). However plausible these suggestions are with respect to minor ailments, they seem less persuasive in situations where more serious conditions are concerned. Some patients, for example, are anosognosic for paralysis of the left leg while acknowledging left arm paralysis (Bisiach, Vallar, Perani, Papagno, \& Berti, 1986). Accounts such as Turnbull's presumably need to assume that, at least for the patients in question, the former impairment poses a greater threat to bodily integrity than the latter.

Aimola Davies et al. (2009) note that a two-factor explanatory framework might incorporate motivational factors yet circumvent the selectivity issue. For example, anosognosia for a given impairment might require both (1) that the patient be unaware of this impairment, perhaps due to somatosensory loss or unilateral neglect; and (2) that the patient be unwilling or unable to acquire other evidence of the impairment. This account, which incorporates motivational processes as a potential second factor, evades the selectivity problem (somatosensory loss might affect the left leg but not the left arm), and also the asymmetry problem (the first factor might involve damage to primarily right-lateralised functions).

\section{Evidence for motivational accounts}

If anosognosic patients are motivated to prevent conscious awareness of their deficits, one might predict that they would show discrepancies between conscious and unconscious awareness of their disability, à la the Bentall et al. conception of persecutory delusions. The evidence available here is intriguing and mixed. Ramachandran (e.g., 1995; Ramachandran \& Blakeslee, 1998) has carried out a range of simple and ingenious experiments to explore the possibility of tacit awareness of disability in anosognosia. In one experiment, he used a "virtual reality box", constructed of cardboard and mirrors, to present an anosognosic patient with the optical illusion that she was moving her paralysed left hand up and down to the rhythm of a metronome. This patient showed no sign of surprise, inconsistent with the hypothesis of tacit awareness of disability. A different experiment was also inconsistent with the notion of implicit awareness. Ramachandran presented left-hemiplegic patients with two water-filled cocktail glasses atop a large tray, and asked them to reach out and take the tray. Whereas nonanosognosic patients reached for the centre of the tray with their good right hand, anosognosic patients reached for the right side with their good hand - despite the fact that this strategy would have caused the glasses to topple. In a third experiment, 
Ramachandran gave anosognosic patients the choice between performing a unimanual task for a small reward, or a bimanual task for a larger reward. Whereas nonanosognosic stroke patients chose the unimanual task, anosognosic patients repeatedly chose the bimanual task that they were in fact unable to perform. Although this result also seems inconsistent with the notion of tacit awareness of disability in anosognosia, Ramachandran notes that one of the patients in this experiment later spoke of performing the bimanual task successfully, with both hands. For Ramachandran, the unusual emphasis on "both hands" bespoke a degree of tacit awareness.

Turnbull et al. (2002) adduced a different form of evidence of implicit awareness. These authors analysed detailed notes from psychoanalytic therapy sessions with five anosognosic and nonanosognosic patients, all of whom had some degree of left-sided motor impairment (see Kaplan-Solms \& Solms, 2000). They reported that anosognosic patients were more likely to experience emotional breakdowns at moments that were preceded by talk of loss, betraying some implicit awareness of their predicaments: "In some cases, the episodes led not only to a temporary tearfulness, but also to a fullyfledged (though short-lived) awareness of the paretic limb" (Turnbull et al., 2002, p. 72). In a more recent investigation, Nardone, Ward, Fotopoulou, and Turnbull (2007) used a dot probe paradigm to measure the emotional impact of different word types. In this task, participants pressed a keyboard key to quickly and accurately classify the colour of a red or blue dot probe flashed onto the computer screen. Presentation of each probe was immediately preceded by a word, which participants were instructed to ignore. Increased response latencies to particular word types are taken to indicate that those words are emotionally threatening. Nardone et al. used words related to disability (e.g., crippled, immobile, paralysed), and found that whereas nonanosognosic patients with severe motor impairments showed reduced latencies (i.e., facilitation) for disability-related words, anosognosic patients showed increased latencies (i.e., interference), suggestive of implicit awareness of their deficits.

It would be interesting to carry out additional investigations of this issue, perhaps utilising appropriate adaptations of the IAT. One way of accomplishing this would be to compare anosognosic and nonanosognosic individuals with hemiplegia for their relative ease of making judgements when (say) self and disabled categories are combined in an IAT (or, better

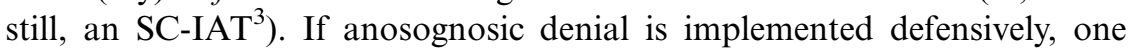
might expect that the response advantage for a "self and healthy condition"

\footnotetext{
${ }^{3}$ Single Category Implicit Association Test (Karpinski \& Steinman, 2006). Because the SC-IAT uses only a single attitude category (e.g., self) rather than pairs of complementary attitude categories (e.g., self vs. other), some of the ambiguity in test score interpretation is eliminated.
} 
TABLE 2

Sample items from the first stage of a Single Category Implicit Association Test (SC-IAT) for self and healthy/disabled

\begin{tabular}{lcc}
\hline Left key category label & Sample items & Right key category label \\
\hline Disabled & & Self or healthy \\
& Me & $* * *$ \\
$* * *$ & Paralysed & $* * *$ \\
& Mobile & $*$ \\
\hline
\end{tabular}

Asterisks indicate correct responses.

(see Table 2) would be significantly reduced for anosognosic individuals relative to controls. ${ }^{4}$

Given the physical limitations of anosognosic patients, and the likelihood of comorbid visual neglect, adapting the IAT or SC-IAT in this manner would not be straightforward. But there seems no reason why careful experimental design could not circumvent these limitations. Pertinent modifications of the basic IAT paradigm might include the use of unimanual responses with the patient's unaffected hand, along with use of a dichotically presented auditory adaptation of the IAT or SC-IAT (see McKay, Arciuli, Atkinson, Bennett, \& Pheils, in press).

Before we move on, we note that anosognosia for left hemiplegia may be accompanied by the disowning of the affected limb (somatoparaphrenia), and even by its personification as belonging to someone else - widely ranging from an existing person ("your hand"), through a dead person (a deceased husband) to an animal ("it's a monkey"; see also Hirstein, 2010 this issue). Extensive clinical experience shows that some degree of left neglect is consistently present, although varying greatly in severity (Feinberg, 2001). Since left neglect involves a biasing of attention rightwards, and withdrawal of attention from the left of space and body (Kinsbourne, 1977, 1993), the disowning and personification may be compensatory to the perplexing loss of familiarity with the affected limb. As the patients do not complain of these strange appendages or ask for them to be removed, it may be that the idiosyncratic labelling is metaphorical (Weinstein, 1991), in some way contributing to an adaptation to perplexing subjective bodily changes.

\section{A TAXONOMY OF FALSE CLAIMS}

We began this paper with two false claims, illustrative of delusion and confabulation, respectively. We finish by outlining a tentative taxonomy of

\footnotetext{
${ }^{4}$ The ideas outlined here have been developed collaboratively with Katerina Fotopoulou.
} 
false claims - a taxonomy that incorporates claims such as these as well as more common, garden-variety false claims. Following McKay and Dennett (in press), we distinguish two broad categories: false claims that arise in the normal course of cognitive functioning and false claims that result from some kind of break (or congenital anomaly) in normal cognitive functioning. By "normal functioning" we refer not to some kind of statistical norm (e.g., not to the way a given individual usually functions), but rather to the adaptive functioning of cognitive systems throughout evolutionary history (see Millikan, 1993). The categories are overlapping rather than discrete, and they admit of intermediate subtypes.

\section{Normal functioning: False claims that reflect design limitations}

Evolution is not a perfect design process. In "designing" cognitive systems, evolution is subject to physical constraints (designs must be within the realm of physical possibility), economic constraints (beyond a certain level, system improvements may yield diminishing returns), historical constraints (the appropriate mutations must occur if selection is to act on them), and "topographical" constraints (selection cannot access optimal design solutions if it must cross fitness valleys to do so). Because evolution is an imperfect design process, the cognitive systems it has equipped us with are bound to be limited.

To give an example, Bayes' theorem specifies the optimal procedure for updating prior beliefs in the light of new evidence (see Coltheart, Menzies, \& Sutton, 2010 this issue). If veridical belief is adaptive, then an organism cannot do better than to revise beliefs in accordance with the Bayesian prescription. No organism, however, can have perfect information - even in principle. So even flawless Bayesians will develop false beliefs, and such beliefs may provide the basis for false claims. These claims thus arise in the normal course of cognitive functioning, and can be accounted for without appeal to motivational factors or neuropsychological deficits. False beliefs, and consequent claims, may also stem from "ecologically rational" departures from Bayesian updating, departures that operate effectively given inevitable limitations of time and computational resources (see Gigerenzer \& Goldstein, 1996).

\section{Normal functioning: False claims that reflect design features}

Not all false claims stem from design limitations - some actually reflect design features. The most obvious examples are false claims made with the deliberate intention to deceive. It has long been realised that individuals 
might increase their own relative fitness by disseminating false information to others. Indeed, modern humans are constantly bombarded with exaggerated and brazenly false claims - to cite just a single source, at the time of writing around 100 billion spam e-mails are sent every day. The false claims in such unsolicited messages are presumably not mistakes-they are motivated attempts to bring about false beliefs in the recipients.

Although individuals who disseminate false information to further their own interests need not believe their own false claims, a number of authors have argued that humans may be evolutionarily predisposed to form false beliefs in certain situations (e.g., Haselton \& Nettle, 2006; Trivers, 1985; see McKay \& Dennett, in press, for a detailed examination of such arguments). Such false beliefs may provide the basis for false claims. As an example, consider the domain of agency detection. In ancestral environments, the malevolent intentions of other agents (whether humans or animals) posed a great threat to survival. A plausible result is that humans gradually evolved cognitive mechanisms specialised for the detection of agency - what Barrett (2000) has termed "hyperactive agent-detection devices" (HADDs). As hyperactive agent detectors, we are biologically predisposed to make false positive errors in ambiguous contexts - imputing agency where there is none. Although such a bias would be adaptive in many scenarios, it might also have destructive consequences - perhaps underpinning accusations of witchcraft and sorcery, for example. Other consequences might include supernatural beliefs and their attendant claims. At present, the dominant evolutionary view of supernatural beliefs is that they are side effects of cognitive mechanisms adapted for other purposes - mechanisms such as HADDs (see Barrett, 2000; Guthrie, 1993).

A final point here is that we may be biologically equipped with tendencies to employ motivational processes "unduly" in certain scenarios. Such processes would distort veridical representations of reality, perhaps by appropriating executive resources (Turnbull \& Solms, 2007). The result would be congenial false beliefs, for example unrealistically positive beliefs about one's children (see McKay \& Dennett, in press). The congenial nature of such beliefs might feature in proximal explanations of their formation; an ultimate explanation, however, would reference their effects on biological fitness. Insofar as such false beliefs would give rise to false claims, therefore, the claims would reflect features of biological design.

\section{Breakages: False claims with purely deficit explanations}

The neuropsychological framework discussed in our earlier section on motivational accounts of delusion provides for an explanation of certain false claims (e.g., the claims of Capgras patients) in terms of breakages in 
normal cognitive functioning - breakages that entail disrupted connections between face-processing areas and the limbic system, for instance. Such cases represent dysfunctional departures from normal operation. Various authors have identified candidate neurocognitive defects potentially associated with a range of delusions. For instance, Frith and colleagues (Frith, 1992; Frith \& Done, 1989; see Feinberg, 1978) have investigated the role of disrupted selfmonitoring in the genesis of alien control delusions. Patients with these delusions believe that external agents such as gods or aliens control their actions. Frith and colleagues have proposed that neuropsychological disruption to "efference copies" - internal copies of motor signals, used to predict the sensory consequences of actions - undermines the normal sense that one has authored the actions. The suggestion is that beliefs about alien control are generated to explain this loss of a sense of agency.

Although it is nicely illustrative of a deficit approach to explaining delusion, it seems to us that the efference copy account is not without difficulties. Reefferent control of movement is highly conserved in evolution, from cockroach to fish to human. In humans it is integral to the accuracy of movements of the eyes, head, arms, and legs. If the operation whereby the efference copy is matched with exafferent feedback were lacking, patients would lack a sense of authorship for all of their actions, including the verbal acts by which they communicate their sense of being under alien control. Moreover, they would exhibit gross inaccuracies in guided movements, inaccuracies that have not been documented. An adjustment of the model seems to be called for.

Deficit accounts are also prominent where confabulation and anosognosia are concerned. For example, it has been suggested that confabulation results from a deficit in the strategic processes implicated in the controlled retrieval of memories (e.g., Burgess \& Shallice, 1996; Conway \& Tacchi, 1996). Levine's (1990) “discovery theory" suggests that anosognosia results when impaired somatosensory awareness of paralysis is coupled with cognitive impairments that prevent integration of other sources of evidence of paralysis (see Aimola Davies et al., 2009, for discussion).

\section{Breakages: False claims that require integrated motivational and neuropsychological deficit explanations}

One can envisage scenarios where premorbid motivational factors interact with neuropsychological deficits. In such cases neuropsychological damage yielding impairments in, say, language or memory functions, would be processed in a motivationally biased fashion, yielding false claims. Much as healthy individuals are prone to unrealistically positive self-evaluations and unrealistic optimism about the future (Taylor, 1989; Taylor \& Brown, 1988), 
neuropsychological patients might underestimate and understate the extent of their impairments, and overestimate and overstate their prospects for recovery.

It is an open question whether the expression of such "positive health illusions" is on a continuum with the avowals and denials of severely anosognosic patients. In the example just considered, the neuropsychological damage is to nonmotivational cognitive components-language functions, for example. This is similar to the two-factor explanation proposed by Aimola Davies et al. (2009), and discussed earlier. The motivational processes operating in these examples are premorbid processes: whether they are ordinary, adaptive motivational processes or congenitally anomalous, exaggerated motivational processes, they are not themselves a direct result of the neuropsychological damage underpinning the first factor impairment. Their operation constitutes a "secondary reaction" to the new psychological reality brought about by the primary neuropsychological impairment (see Fotopoulou, 2010 this issue).

On accounts such as Ramachandran's (e.g., 1995; Ramachandran \& Blakeslee, 1998) account of anosognosia, in contrast, the neuropsychological damage can be construed as affecting motivational structures - damage to neurological structures that constrain the implementation of psychological defences, for example (see, also, Fotopoulou's [2010 this issue] account of confabulation). Such breakage thus liberates or releases motivational processes: the motivational factor is itself a consequence of the neuropsychological damage, qualitatively and quantitatively distinct from the "positive illusions" of healthy people. Such accounts are thus genuinely "neuropsychodynamic" or "neuropsychoanalytic".

\section{CONCLUSION}

The nature and extent of overlap between the clinical concepts of confabulation, delusion, and anosognosia remains unclear. In this paper we have considered the role of motivational factors in each symptom. Although space considerations have precluded an exhaustive review of relevant studies in each domain, we hope to have conveyed a sense of the range of motivational theories available, and the types of evidence adduced in support of these theories. In our view the evidence is strongly suggestive of a role for motivational factors in each domain. We have put forward a taxonomy of false claims that incorporates both clinical and garden-variety variants. We suspect that the most comprehensive accounts of the false claims observed in clinical settings will occupy the final category of our taxonomy, integrating both motivational factors and neuropsychological deficits. 


\section{REFERENCES}

Adler, A. (1929). Melancholia and paranoia. In A. Adler (Ed.), The practice and theory of individual psychology. London: Routledge \& Kegan Paul. (Original work published 1914)

Aimola Davies, A. M., Davies, M., Ogden, J. A., Smithson, M., \& White, R. C. (2009). Cognitive and motivational factors in anosognosia. In T. Bayne \& J. Fernández (Eds.), Delusion and selfdeception: Affective and motivational influences on belief formation (pp. 187-225). Hove, UK: Psychology Press.

American Psychiatric Association. (2000). Diagnostic and statistical manual of mental disorders (4th ed., Text revision [DSM-IV-TR]). Washington, DC: Author.

Banov, M. D., Kulick, A. R., Oepen, G., \& Pope, H. G., Jr. (1993). A new identity for misidentification syndromes. Comprehensive Psychiatry, 34(6), 414-417.

Barrett, J. L. (2000). Exploring the natural foundations of religion. Trends in Cognitive Sciences, $4(1), 29-34$.

Bayne, T., \& Fernández, J. (2009). Delusion and self-deception: Mapping the terrain. In T. Bayne \& J. Fernández (Eds.), Delusion and self-deception: Affective and motivational influences on belief formation (pp. 1-21). Hove, UK: Psychology Press.

Becker, E. (1973). The denial of death. New York: Free Press.

Bell, D. (2003). Paranoia. Cambridge, UK: Icon Books.

Bentall, R., \& Swarbrick, R. (2003). The best laid schemas of paranoid patients: Autonomy, sociotropy and need for closure. Psychology and Psychotherapy: Theory, Research and Practice, 76(2), 163-171.

Bentall, R. P., \& Kaney, S. (1996). Abnormalities of self-representation and persecutory delusions: A test of a cognitive model of paranoia. Psychological Medicine, 26, 1231-1237.

Bisiach, E., \& Geminiani, G. (1991). Anosognosia related to hemiplegia and hemianopia. In G. P. Prigatano \& D. L. Schacter (Eds.), Awareness of deficit after brain injury: Clinical and theoretical issues (pp. 17-39). Oxford, UK: Oxford University Press.

Bisiach, E., Vallar, G., Perani, D., Papagno, C., \& Berti, A. (1986). Unawareness of disease following lesions of the right hemisphere: Anosognosia for hemiplegia and anosognosia for hemianopia. Neuropsychologia, 24, 471-482.

Bonhoeffer, K. (1901). Die akuten Geisteskrankheiten der Gewohnheitstrinker: Eine Klinische Studie. Jena, Germany: Gustav Fischer.

Brighetti, G., Bonifacci, P., Borlimi, R., \& Ottaviani, C. (2007). "Far from the heart far from the eye": Evidence from the Capgras delusion. Cognitive Neuropsychiatry, 12(3), 189-197.

Burgess, P. W., \& Shallice, T. (1996). Confabulation and the control of recollection. Memory, 4, 359-411.

Campbell, W. K., Bosson, J. K., Goheen, T. W., Lakey, C. E., \& Kernis, M. H. (2007). Do narcissists dislike themselves "deep down inside"? Psychological Science, 18(3), 227-229.

Capgras, J., \& Carette, P. (1924). Illusion de sosies et complexe d'oedipe. Annales MedicoPsychologiques, 82, 48-68.

Capgras, J., \& Reboul-Lachaux, J. (1923). Illusion des sosies dans un delire systematise chronique. Bulletin de la Societe Clinique de Medicine Mentale, 2, 6-16.

Christodoulou, G. N. (1976). Delusional hyper-identifications of the Fregoli type: Organic pathogenetic contributors. Acta Psychiatrica Scandinavica, 54(5), 305-314.

Christodoulou, G. N. (1977). The syndrome of Capgras. British Journal of Psychiatry, 130, 556-564.

Colbert, S. M., \& Peters, E. R. (2002). Need for closure and jumping-to-conclusions in delusionprone individuals. Journal of Nervous and Mental Disease, 190(1), 27-31.

Colbert, S. M., Peters, E. R., \& Garety, P. A. (2006). Need for closure and anxiety in delusions: A longitudinal investigation in early psychosis. Behaviour Research and Therapy, 44(10), 1385-1396. 
Coltheart, M., Menzies, P., \& Sutton, J. (2010). Abductive inference and delusional belief. Cognitive Neuropsychiatry, 15(1/2/3), 261-287.

Conway, M. A., \& Tacchi, P. C. (1996). Motivated confabulation. Neurocase, 2, 325-339.

Cotard, J. (1882). Du délire des négations. Archives de Neurologie, 4, 150-170, 282-295.

Cutting, J. (1978). Study of anosognosia. Journal of Neurology. Neurosurgery and Psychiatry, 41, 548-555.

David, A. S. (1999). On the impossibility of defining delusions. Philosophy, Psychiatry, and Psychology, 6(1), 17-20.

Davies, M. (2009). Delusion and motivationally biased belief: Self-deception in the two-factor framework. In T. Bayne \& J. Fernández (Eds.), Delusion and self-deception: Affective and motivational influences on belief formation (pp. 71-86). Hove, UK: Psychology Press.

Davies, M., Aimola Davies, A. M., \& Coltheart, M. (2005). Anosognosia and the two-factor theory of delusion. Mind and Language, 20, 209-236.

Davies, M., \& Coltheart, M. (2000). Introduction: Pathologies of belief. In M. Coltheart \& M. Davies (Eds.), Pathologies of belief (pp. 1-46). Malden, MA: Blackwell Publishers.

De Pauw, K. W. (1994). Psychodynamic approaches to the Capgras delusion: A critical historical review. Psychopathology, 27, 154-160.

Ellis, H. D., Quayle, A. H., de Pauw, K. W., Szulecka, T. K., Young, A. W., \& Kolkiewicz, L. A. (1996). Delusional misidentification of inanimate objects: A literature review and neuropsychological analysis of cognitive deficits in two cases. Cognitive Neuropsychiatry, 1(1), 27-40.

Ellis, H. D., \& Young, A. W. (1990). Accounting for delusional misidentifications. British Journal of Psychiatry, 157, 239-248.

Ellis, H. D., Young, A. W., Quayle, A. H., \& de Pauw, K. W. (1997). Reduced autonomic responses to faces in Capgras delusion. Proceedings of the Royal Society of London: Biological Sciences, B264, 1085-1092.

Enoch, M. D., \& Ball, H. N. (2001). Uncommon psychiatric syndromes (4th ed.). London: Arnold.

Feinberg, I. (1978). Efference copy and corollary discharge: Implications for thinking and its disorders. Schizophrenia Bulletin, 4, 636-640.

Feinberg, T. E. (2001). Altered egos. Oxford, UK: Oxford University Press.

Feinberg, T. E., \& Keenan, J. P. (2005). Where in the brain is the self? Consciousness and Cognition, 14(4), 661-678.

Fotopoulou, A. (2010). The affective neuropsychology of confabulation and delusion. Cognitive Neuropsychiatry, 15(1/2/3), 38-63.

Fotopoulou, A., Conway, M., Griffiths, P., Birchall, D., \& Tyrer, S. (2007). Self-enhancing confabulation: Revisiting the motivational hypothesis. Neurocase, 13(1), 6-15.

Fotopoulou, A., Conway, M. A., Tyrer, S., Birchall, D., Griffiths, P., \& Solms, M. (2008). Is the content of confabulation positive? An experimental study. Cortex, 44, 764-772.

Freeman, D., Garety, P. A., Kuipers, E., Colbert, S., Jolley, S., Fowler, D., et al. (2006). Delusions and decision-making style: Use of the Need for Closure Scale. Behaviour Research and Therapy, 44(8), 1147-1158.

Freud, S. (1895). Draft H. In J. Strachey (Ed.), The standard edition of the complete psychological works of Sigmund Freud (Vol. 1, pp. 206-213). London: Hogarth Press and the Institute of Psychoanalysis.

Frith, C. D. (1992). The cognitive neuropsychology of schizophrenia. Hove, UK: Lawrence Erlbaum Associates Ltd.

Frith, C. D., \& Done, D. J. (1989). Experiences of alien control in schizophrenia reflect a disorder in the central monitoring of action. Psychological Medicine, 19, 359-363.

Garety, P. A., \& Freeman, D. (1999). Cognitive approaches to delusions: A critical review of theories and evidence. British Journal of Clinical Psychology, 38, 113-154.

Gerrans, P. (2000). Refining the explanation of Cotard's delusion. Mind and Language, 15(1), 111-122. 
Gerrans, P. (2002). A one-stage explanation of the Cotard delusion. Philosophy, Psychiatry, and Psychology, 9(1), 47-53.

Gigerenzer, G., \& Goldstein, D. G. (1996). Reasoning the fast and frugal way: Models of bounded rationality. Psychological Review, 103(4), 650-669.

Greenberg, J., Pyszczynski, T., \& Solomon, S. (1986). The causes and consequences of the need for self-esteem: A terror management theory. In R. F. Baumeister (Ed.), Public self and private self (pp. 189-212). New York: Springer-Verlag.

Greenwald, A. G., \& Farnham, S. D. (2000). Using the Implicit Association Test to measure selfesteem and self-concept. Journal of Personality and Social Psychology, 79(6), 1022-1038.

Greenwald, A. G., McGhee, D. E., \& Schwartz, J. L. K. (1998). Measuring individual differences in implicit cognition: The implicit association test. Journal of Personality and Social Psychology, 74(6), 1464-1480.

Guthrie, S. E. (1993). Faces in the clouds: A new theory of religion. Oxford, UK: Oxford University Press.

Hamilton, A. (2007). Against the belief model of delusion. In M. C. Chung, K. W. M. Fulford, \& G. Graham (Eds.), Reconceiving schizophrenia (pp. 217-234). Oxford, UK: Oxford University Press.

Haselton, M. G., \& Nettle, D. (2006). The paranoid optimist: An integrative evolutionary model of cognitive biases. Personality and Social Psychology Review, 10(1), 47-66.

Heilman, K. M. (2009). Anosognosia for hemiplegia: A confabulatory state. In W. Hirstein (Ed.), Confabulation: Views from neuroscience, psychiatry, psychology, and philosophy (pp. 189-202). Oxford, UK: Oxford University Press.

Hirstein, W. (2005). Brain fiction: Self-deception and the riddle of confabulation. Cambridge, MA: MIT Press.

Hirstein, W. (2010). The misidentification syndromes as mindreading disorders. Cognitive Neuropsychiatry, 15(1/2/3), 233-260.

Hirstein, W. S., \& Ramachandran, V. S. (1997). Capgras syndrome: A novel probe for understanding the neural representation of the identity and familiarity of persons. Proceedings of the Royal Society of London: Biological Sciences, 264B, 437-444.

Jordan, C. H., Spencer, S. J., Zanna, M. P., Hoshino-Browne, E., \& Correll, J. (2003). Secure and defensive high self-esteem. Journal of Personality and Social Psychology, 85(5), 969-978.

Kaplan-Solms, K. L., \& Solms, M. (2000). Clinical studies in neuropsychoanalysis: Introduction of a depth neuropsychology. London: Karnac Books.

Karpinski, A., \& Steinman, R. B. (2006). The Single Category Implicit Association Test as a measure of implicit social cognition. Journal of Personality and Social Psychology, 91(1), 16-32.

Kinderman, P. (1994). Attentional bias, persecutory delusions and the self-concept. British Journal of Medical Psychology, 67(1), 53-66.

Kinderman, P., \& Bentall, R. P. (1996). Self-discrepancies and persecutory delusions: Evidence for a model of paranoid ideation. Journal of Abnormal Psychology, 105(1), 106-113.

Kinderman, P., \& Bentall, R. P. (1997). Causal attributions in paranoia and depression: Internal, personal, and situational attributions for negative events. Journal of Abnormal Psychology, 106(2), 341-345.

Kinsbourne, M. (1977). Hemi-neglect and hemisphere rivalry. In E. A. Weinstein \& R. P. Friedland (Eds.), Hemi-inattention and hemisphere specialization (pp. 41-49). New York: Raven Press.

Kinsbourne, M. (1993). Orientational bias model of unilateral neglect: Evidence from attentional gradients within hemispace. In I. H. Robertson \& J. C. Marshall (Eds.), Unilateral neglect: Clinical and experimental studies (pp. 63-86). Hove, UK: Lawrence Erlbaum Associates Ltd.

Krstev, H., Jackson, H., \& Maude, D. (1999). An investigation of attributional style in first-episode psychosis. British Journal of Clinical Psychology, 38, 181-194.

Kruglanski, A. W. (1989). Lay epistemics and human knowledge: Cognitive and motivational bases. New York: Plenum. 
Langdon, R., \& Coltheart, M. (2000). The cognitive neuropsychology of delusions. Mind and Language, 15(1), 183-216.

Levine, D. N. (1990). Unawareness of visual and sensorimotor defects: A hypothesis. Brain and Cognition, 13, 233-281.

Lyon, H. M., Kaney, S., \& Bentall, R. P. (1994). The defensive function of persecutory delusions: Evidence from attribution tasks. British Journal of Psychiatry, 164(5), 637-646.

Lyon, H. M., Startup, M., \& Bentall, R. P. (1999). Social cognition and the manic defense: Attributions, selective attention, and self-schema in bipolar affective disorder. Journal of Abnormal Psychology, 108(2), 273-282.

Martin, J. A., \& Penn, D. L. (2002). Attributional style in schizophrenia: An investigation in outpatients with and without persecutory delusions. Schizophrenia Bulletin, 28(1), 131-142.

McKay, R., Arciuli, J., Atkinson, A., Bennett, E., \& Pheils, E. (in press). Lateralisation of selfesteem: An investigation using a dichotically presented auditory adaptation of the Implicit Association Test. Cortex. doi: 10.1016/j.cortex.2009.05.004

McKay, R., \& Cipolotti, L. (2007). Attributional style in a case of Cotard delusion. Consciousness and Cognition, 16, 349-359.

McKay, R., \& Dennett, D. (in press). The evolution of misbelief. Behavioral and Brain Sciences.

McKay, R., Langdon, R., \& Coltheart, M. (2007a). The defensive function of persecutory delusions: An investigation using the Implicit Association Test. Cognitive Neuropsychiatry, 12(1), 1-24.

McKay, R., Langdon, R., \& Coltheart, M. (2007b). Jumping to delusions? Paranoia, probabilistic reasoning and need for closure. Cognitive Neuropsychiatry, 12(4), 362-376.

McKay, R. T. (2004). "Sleights of mind": Delusions and self-deception. Unpublished PhD thesis, Macquarie University, Sydney.

McWilliams, N. (1994). Psychoanalytic diagnosis: Understanding personality structure in the clinical process. New York: Guilford Press.

Mele, A. R. (1997). Real self-deception. Behavioral and Brain Sciences, 20(1), 91-136.

Mele, A. R. (2009). Self-deception and delusions. In T. Bayne \& J. Fernández (Eds.), Delusion and self-deception: Affective and motivational influences on belief formation (pp. 55-69). Hove, UK: Psychology Press.

Metcalf, K., Langdon, R., \& Coltheart, M. (2010). The role of personal biases in the explanation of confabulation. Cognitive Neuropsychiatry, 00(00), 000-000.

Millikan, R. (1993). White queen psychology and other essays for Alice. Cambridge, MA: MIT Press.

Mojtabai, R. (1994). Fregoli syndrome. Australian and New Zealand Journal of Psychiatry, 28, 458-462.

Moritz, S., Werner, R., \& von Collani, G. (2006). The inferiority complex in paranoia readdressed: A study with the Implicit Association Test. Cognitive Neuropsychiatry, 11(4), 402-415.

Moscovitch, M. (1995). Confabulation. In D. L. Schacter (Ed.), Memory distortion: How minds, brains, and societies reconstruct the past. Cambridge, MA: Harvard University Press.

Nardone, I. B., Ward, R., Fotopoulou, A., \& Turnbull, O. H. (2007). Attention and emotion in anosognosia: Evidence of implicit awareness and repression? Neurocase, 13, 438-445.

Nasar, S. (1998). A beautiful mind. New York: Simon \& Schuster.

Neuberg, S. L., Judice, T. N., \& West, S. G. (1997). What the Need for Closure Scale measures and what it does not: Toward differentiating among related epistemic motives. Journal of Personality and Social Psychology, 72, 1396-1412.

Peters, E., Day, S., \& Garety, P. A. (1997). From preconscious to conscious processing - where does the abnormality lie in delusions? Schizophrenia Research, 24, 120.

Peters, E. R., Day, S., \& Garety, P. A. (1996). The Peters et al. Delusions Inventory (PDI): New norms for the 21-item version. Schizophrenia Research, 18, 118. 
Peterson, C., Semmel, A., von Baeyer, C., Abramson, L. Y., Metalsky, G. I., \& Seligman, M. E. P. (1982). The Attributional Style Questionnaire. Cognitive Therapy and Research, 6(3), 287-300.

Ramachandran, V. S. (1995). Anosognosia in parietal lobe syndrome. Consciousness and Cognition, $4(1), 22-51$.

Ramachandran, V. S., \& Blakeslee, S. (1998). Phantoms in the brain: Human nature and the architecture of the mind. London: Fourth Estate.

Raschka, L. B. (1981). The Capgras syndrome. Canadian Journal of Psychiatry, 26(3), 207-208.

Reid, I., Young, A. W., \& Hellawell, D. J. (1993). Voice recognition impairment in a blind Capgras patient. Behavioural Neurology, 6, 225-228.

Rosler, A., Holder, G., \& Seifritz, E. (2001). Canary Capgras. Journal of Neuropsychiatry and Clinical Neurosciences, 13(3), 429.

Schnider, A. (2008). The confabulating mind: How the brain creates reality. Oxford, UK: Oxford University Press.

Silva, J. A., Leong, G. B., Longhitano, M., \& Botello, T. E. (1991). Delusion of fetal duplication in a Capgras patient. Canadian Journal of Psychiatry, 336, 46-47.

Smith, N., Freeman, D., \& Kuipers, E. (2005). Grandiose delusions: An experimental investigation of the delusion as defense. Journal of Nervous and Mental Disease, 193(7), 480-487.

Somerfield, D. (1999). Capgras syndrome and animals. International Journal of Geriatric Psychiatry, 14, 892-894.

Stephens, G. L., \& Graham, G. (2004). Reconceiving delusion. International Review of Psychiatry, 16(3), 236-241.

Stone, T., \& Young, A. W. (1997). Delusions and brain injury: The philosophy and psychology of belief. Mind and Language, 12, 327-364.

Stroop, J. R. (1935). Studies of interference in serial verbal reactions. Journal of Experimental Psychology, 18, 643-662.

Taylor, S. E. (1989). Positive illusions: Creative self-deception and the healthy mind. New York: Basic Books.

Taylor, S. E., \& Brown, J. D. (1988). Illusion and well-being: A social psychological perspective on mental health. Psychological Bulletin, 103, 193-210.

Trivers, R. L. (1985). Social evolution. Menlo Park, CA: Benjamin Cummings.

Turnbull, O. H., Jones, K., \& Reed-Screen, J. (2002). Implicit awareness of deficit in anosognosia? An emotion-based account of denial of deficit. Neuro-Psychoanalysis, 4, 69-86.

Turnbull, O. H., \& Solms, M. (2007). Awareness, desire, and false beliefs: Freud in the light of modern neuropsychology. Cortex, 43, 1083-1090.

Vazquez, C., Diez-Alegria, C., Hernandez-Lloreda, M. J., \& Moreno, M. N. (2008). Implicit and explicit self-schema in active deluded, remitted deluded, and depressed patients. Journal of Behavior Therapy and Experimental Psychiatry, 39, 587-599.

Webster, D. M., \& Kruglanski, A. W. (1994). Individual differences in need for cognitive closure. Journal of Personality and Social Psychology, 67(6), 1049-1062.

Weinstein, E. A. (1991). Anosognosia and denial of illness. In G. P. Prigatano \& D. L. Schacter (Eds.), Awareness of deficit after brain injury: Clinical and theoretical issues (pp. 240-257). New York: Oxford University Press.

Weinstein, E. A., \& Kahn, R. L. (1950). The syndrome of anosognosia. Archives of Neurology and Psychiatry, 64, 772-791.

Weinstein, E. A., \& Kahn, R. L. (1955). Denial of illness: Symbolic and physiological aspects. Springfield, IL: Charles C. Thomas.

Winters, K. C., \& Neale, J. M. (1985). Mania and low self-esteem. Journal of Abnormal Psychology, 94, 282-290.

Wright, S., Young, A. W., \& Hellawell, D. J. (1993). Sequential Cotard and Capgras delusions. British Journal of Clinical Psychology, 32(3), 345-349. 


\section{McKAY AND KINSBOURNE}

Young, A. W. (2000). Wondrous strange: The neuropsychology of abnormal beliefs. Mind and Language, 15(1), 47-73.

Young, A. W., \& Leafhead, K. M. (1996). Betwixt life and death: Case studies of the Cotard delusion. In P. W. Halligan \& J. C. Marshall (Eds.), Method in madness: Case studies in cognitive neuropsychiatry. Hove, UK: Lawrence Erlbaum Associates Ltd.

Young, A. W., Leafhead, K. M., \& Szulecka, T. K. (1994). The Capgras and Cotard delusions. Psychopathology, 27(3-5), 226-231.

Zigler, E., \& Glick, M. (1988). Is paranoid schizophrenia really camouflaged depression? The American Psychologist, 43, 284-290. 